\title{
Ricardo Palma dentro del teatro de la independencia peruana. Aspectos ideológicos en Rodil (1851)
}

\author{
Miguel Ángel Vallejo Sameshima \\ Universidad de Granada, Granada - España \\ vallejo.sameshima@gmail.com
}

\section{Resumen}

El presente trabajo contextualiza el drama Rodil, único conocido de Ricardo Palma, dentro del teatro sobre la independencia del Perú y la estética del romanticismo peruano, para, mediante un análisis de los actos de habla, interpretar los aspectos ideológicos de la pieza.

Palabras clave: Teatro de la independencia, romanticismo peruano, proyecto político criollo.

\section{Abstract}

This paper contextualizes Rodil, the only known drama by Ricardo Palma that belongs to the theatre about the Peruvian independence and the aesthetic of the Peruvian romanticism. The aim is to interpreter the ideological aspects of the play through an analysis of the acts of speaking.

Keywords: Tether of Independence, Peruvian romanticsm, creole political project 
Miguel Ángel Vallejo Sameshima, Magister en Literatura y Teatro por la Universidad de Granada (España) y Bachiller en Literatura por la UNMSM. Ha publicado once libros, de ficción y no ficción, para niños y adultos, entre ellos la novela $L a$ muerte no tiene ojos (2016), el libro de testimonios Vallejo Urreta. Historias de una familia peruana (2015). Relatos suyos aparecen en antologías y revistas nacionales y extranjeras. En 2016 fue reconocido como uno de los escritores nikkei peruanos más destacados. Mención honrosa en el Concurso Nueva Dramaturgia Peruana, del Ministerio de Cultura del Perú, en la categoría Teatro para la Memoria (2017), Mención honrosa en la 6ta Bienal de Cuento Infantil del Instituto Cultural Peruano Norteamericano (2014). Ganó el II Concurso de Intervenciones Artísticas del Teatro de San Marcos (2005). 
Las obras sobre la Independencia durante el período en que esta se gestó fueron herramientas de agitación y propaganda a favor de la causa que defendían. La mayoría de estas fueron loas, entremeses o proclamas dramáticas, salvo algunas más elaboradas como Los patriotas de Lima en la noche feliz (1821), atribuida a Miguel del Carpio, que si bien tenían una extensión mayor, tampoco contaban con un conflicto claro ni personajes definidos.

Algunas de las características generales de las piezas de este período sobre la independencia son: estética neoclásica, brevedad, falta de trama, personajes sin definir, así como presentar largos discursos con ideas políticas claras y directas, una visión maniquea de los personajes y un uso de actos de habla para injuriar o ridiculizar al adversario mientras se destaca el valor y la nobleza del bando por el cual se toma partido, en especial en las numerosas loas y entremeses. De estos actos de habla ${ }^{1}$ se desprenden, tanto en las obras a favor como en contra de la independencia, valores cristianos y de la civilización occidental afines a la causa que defienden.

Estas obras a favor y en contra de la independencia tienen muy baja calidad estética, en parte por la premura en presentarlas para utilizarlas como herramientas de propaganda, en parte por la dificultad de representar un contexto complejo como una sublevación o una guerra mientras esta ocurre. Del mismo modo, complicaba estas representaciones la ausencia de una tradición teatral o narrativa propias del país. Así, las obras en contra de la independencia deslegitiman la causa patriota acusándola de interesada y destructora de valores cristianos, mientras las

l Usamos el análisis de actos de habla según las ideas de Ricoeur (1995) desarrolladas posteriormente por los pragmatistas. Esto es, revisar e interpretar los tres tipos de actos de habla. El locutivo es lo dicho literalmente. El ilocutivo, además de decir, puede ejecutar una acción, como en un proceso judicial, o el intento de persuadir o seducir, y contiene la intención real del locutivo. Y el perlocutivo son las consecuencias del acto ilocutivo, si este fue exitoso o no. 
obras a favor idealizan un futuro republicano, generando una épica nacional, pero sin ideas claras ni valores definidos ${ }^{2}$.

Las primeras décadas de la república no vieron un gran cambio en la estética teatral. En lo político se vivió una democracia alterada por sucesivos golpes de Estado. En estas circunstancias, el arte de los criollos republicanos no marcará una gran ruptura con el virreinal. De hecho, solo unas pocas décadas luego de la independencia se habrá perdido el interés por el tema. El público, de acuerdo con Sotomayor (1990), se mantuvo en el gusto anterior de óperas y, sobre todo, zarzuelas, con poca presencia de dramas. Rivera Saavedra (2005) apunta que se montaba una gran cantidad de obras con escaso público, y las autoridades no tenían ningún interés en fomentar el teatro. Esto último, quizá, debido a que no se consolidaron grupos de poder o partidos políticos con intereses a largo plazo o con proyectos que pudieran consolidarse en el tiempo.

\section{El teatro de Palma}

En este contexto, Ricardo Palma debuta como escritor haciendo teatro. En La bohemia de mi tiempo (1886) afirma haber sido un dramaturgo romántico. Su primera obra fue El hijo del Sol (1849), que no se representó3. Le siguió La hermana del verdugo (1851) de la que considera que no hay "correspondencia entre la historia y la ficción dramática” (295) porque el reparto indica

2 Conclusiones de la tesis de maestría de quien escribe este artículo, titulada Aproximaciones al teatro sobre la independencia del Perú. El papel de los sujetos subordinados, sustentada en la Universidad de Granada. La investigación prosigue ahora en una tesis doctoral en la misma casa de estudios.

3 Se anunció en el diario El Comercio el 28 de noviembre de 1849, junto a El Barquero y el Virrey de Nicolás Corpancho, en un texto que pedía que se representara en diciembre. Holguín (1994) considera que puede haber sido el argumento base para su tradición "El hermano de Atahualpa", donde se refiere a los incas como hijos del Sol. 
como personaje a un inquisidor, y la Inquisición no existió en los tiempos del personaje histórico Juan Enríquez. En detalle, afirma que La hermana del verdugo trata sobre el personaje real de Cusco, que mató a Gonzalo Pizarro y a Francisco de Carvajal, pero dice: "Mi Juan Enriquez se parecía al de la historia como una góndola de pescador a un navío de tres puentes. Argumento y caracteres eran desatinados hasta dejarlo de sobra" (Palma, 1948 [1886], p. 42).

El tercer drama fue La muerte o la libertad (1851), sobre esta obra Holguín (1994) señala que tuvo un estreno dentro de las celebraciones por la independencia, el 27 de julio. Alrededor de veinte dramas se escribieron para esas fechas, se representaron obras europeas con temas patrióticos en el Teatro Variedades y hubo fiestas con bandas de música por la ciudad, corridas de toros y un espectáculo de fuegos artificiales: ello opacó las reseñas sobre la pieza.

Rodil (1851) sería el cuarto drama de Palma ${ }^{4}$, quien dice de esta pieza que "El primer acto fue recibido con tibieza... pero en el segundo, ponía yo en boca del galán alusiones políticas de actualidad, zurraba la bandana al ministerio, y decía pestes contra la ley de represión dictada no cuando Rodil comía pan en el Callao, sino pocos días antes de salir a luz ese precioso fruto de mi numen" (Palma, 1948 [1886], p. 43).

4 Asimismo, Palma escribió cuatro comedias: Los piquines de la niña (1855), Criollos y afrancesados (1857), iSanguijuela! (1858) y El santo de Panchita (1858, con Manuel Ascencio Segura, la única de la que queda registro junto a Rodil). Sobre El santo de Panchita (1858) menciona que hubo avisos promocionales en diarios donde se hablaba de dos autores anónimos, aunque es probable que mucha gente supiera de quiénes se trataba. A su vez, recuerda que Palma en su "Preámbulo biográfico y noticiero", asegura que su participación en la obra fue pequeña, limitándose a redactar "una escena del segundo acto, algo del tercero y ciertas variantes de doña Fila”. Describe la pieza como una comedia de enredos por amor con limeñismos, peruanismos y otros americanismos, que Segura usaba ya como parte de su poética, y Palma emplearía luego. 
Luego de sus comedias deja de escribir teatro: "Hice un auto de fe con mis tonterías escénicas y... c'est fini, no volví a escribir dramas" (43). Sin embargo, también se refiere a la pieza como "mi caballo de batalla, mi gran triunfo" (43).

Esta relación de amor y odio con su dramaturgia no niega que sus años como dramaturgo vayan moldeando su estética y su perspectiva ideológica maduras.

\section{Estética del romanticismo peruano}

Situamos a Rodil dentro de la estética y propuesta ideológica del romanticismo, no solo por la definición del autor sino por elementos textuales, pero contextualizados dentro de lo que representó esta corriente en nuestro país. En el prólogo de Augusto Tamayo Vargas a La bohemia de mi tiempo, asegura que en el romanticismo peruano:

No se percibe claramente el ideal de la libertad dentro de la Naturaleza que mueve el romanticismo europeo. Y tampoco marca en nuestros poetas románticos aquel sentimiento de vivir y morir por la literatura que es el trasfondo de la etapa romántica. Nuestro romanticismo tiene un preciso antecedente: Melgar. En él se conjugan los ideales de libertad política y libertad literaria; busca los motivos vernaculares; y plantea al individuo dentro de una naturaleza (en Palma, 1948 [1886], p. 12).

Para Silva-Santisteban (2001), el romanticismo en el teatro no alcanzó el mismo nivel que en la poesía, y asegura que es un reflejo de lo romántico español y francés, considerándolo una corriente arrebatada, espontánea y sentimental, que se opone a la rigidez del teatro neoclásico mientras intenta adoptar una visión histórica. 
Acerca de los aspectos discursivos y de contenido del romanticismo peruano, concordamos con Balta en su definición: "A diferencia del costumbrismo, los argumentos de los románticos no tienen diatriba alguna, escapan de su realidad social revestidos por un abuso de elementos antitéticos" (2000, p. 23). A su vez, Valero (2005) afirma que el romanticismo peruano debió enfrentarse a una incapacidad para entender el pasado. Específicamente sobre Palma, considera que si bien humaniza e ironiza sobre personajes y situaciones coloniales en sus tradiciones maduras, a partir de textos históricos, sus primeras tradiciones guardan un exotismo romántico al retratar al imperio incaico.

Por su parte, Porras Barrenechea (1969) afirma que luego de la independencia, en el Perú:

El idioma, la cultura, el sentimiento religioso y con ellos las costumbres, las fiestas y los trajes, y hasta las leyes, siguen siendo españoles... En la literatura, la única señal de transformación son los periódicos, desbordados y procaces, que injurian la verdadera concepción republicana, y los ensayos más cultos e inspirados de crear un género criollo, alegre y costumbrista, sobre el perenne pedestal de la agudeza limeña (42).

Añade Porras que el romanticismo peruano toma el modelo europeo, que se deja sentir sobre todo en el teatro, y que en este hubo una fascinación por lo medieval, como se aprecia en algunas obras de Corpancho. Nosotros consideramos que Palma en Rodil logra plasmar un tema propio aproximándose a una sensibilidad nacional, como harían luego Márquez y Salaverry. Y que en esta pieza se insinúan ya algunos mecanismos para ficcionalizar la historia, que se notarán sobre todo en sus tradiciones. 


\section{Matices ideológicos}

Rodil (1851) se desarrolla con aspectos ficcionales a partir de la figura de José Ramón Rodil y Gayoso (Lugo, 1789-Madrid, 1853), militar que participó en la campaña de defensa del virreinato en el norte de Chile y luego fue destacado al Callao como comandante. A pesar de la toma de este puerto y de Lima por parte de los patriotas, los españoles encabezados por Rodil retoman el control de la fortaleza del Callao, el Real Felipe, debido a una insurrección de tropas independentistas por deudas en sus salarios. Obnubilado por el poder, Rodil decide no aceptar la rendición y se acantona en el Real Felipe, gobernándolo con ley marcial. En enero de 1826 la mayoría de soldados y civiles bajo su mando habían muerto, y solo entonces se rindió. Bolívar, entonces gobernador del Perú, le permitió ir a España, llevando las banderas de sus regimientos. En 1831 la Corona Española le otorgó el título de marqués.

La obra de Palma, escrita en verso irregular, se ambienta en el sitio del Real Felipe y muestra a un Rodil enloquecido. Si bien tiene elementos de la literatura gótica, no contempla situaciones fantásticas ni ahonda en el terror o lo sobrenatural. En cambio, busca reconstruir la historia de los primeros años luego de la independencia a la vez que plantea alegorías sobre la visión del Virreinato y de la República, así como de los españoles y los patriotas/criollos.

En un balance general, concordamos con Holguín (1994) cuando afirma que en Rodil

Cada personaje, sobre todo los masculinos, representa determinados valores o antivalores: César, el patriotismo, el talento, el honor; Gilberto, el republicanismo, la pobreza, la honradez y también el patriotismo; Rodil, la falsedad, la soberbia, la presión sin límites, la crueldad; y Vicente, 
el cinismo, la venalidad, el interés. Los principales papeles femeninos - María y Margarita - expresan la nobleza de los sentimientos puros, la ternura, la ingenuidad, el orgullo, la dignidad. El tema general de la obra es romántico, con profusión de sentimientos y expresiones de amor, desconsuelo, venganza, pasión, patriotismo, etc., en medio de lances propios del gusto de la época (305).

Haremos una breve descripción del argumento de Palma, con citas de sus largos diálogos, buscando los aspectos ideológicos. En el "Prólogo. Pagar con oro el honor", ambientado en Lima a inicios del siglo XIX, la acción se inicia cuando Rodil rechaza la responsabilidad de haber embarazado a María, hermana de Gilberto, y toma la posición del noble despótico.

En esta situación, Gilberto se queja de los nobles" :Y esos nobles, ioh, María! / mientras el pueblo devora / su angustia desgarradora / gozan en lúbrica orgía" (Palma, 1953, p. 14). Y añade el mismo Gilberto: "A ser / sólo víctimas nacimos / Goza, pueblo, con tu yugo, canta al son de tu cadena / mientras el goce enajena / en la orgía a tu verdugo" (16), y “¿Y me habláis de vuestra honra? / ¿Desde cuándo / pagan los nobles el subido precio / de conducirla al templo, los amores / de una mujer liviana, hija del pueblo" (20). Luego, Gilberto jura venganza y amenaza a Rodil.

En el "Acto Primero. La espada y el pincel", ambientado en Lima en 1825, en un taller de pintura, Rodil quiere el retrato que César pinta de Margarita y se lo lleva arrogante aun ante la negativa de los pintores, y avienta un bolsillo de oro. César jura vengarse, con una épica que incluye la gesta por la independencia:

5 Ortografía del original. 
Patria mía! Si pudo la España / por tres siglos tu brillo oprimir, / tienes hijos que verte ambicionar / sin cadenas y libre y feliz / Del destino las leyes acaso / te reservan un gran porvenir, / que tus hijos sabrán conquistarte / o con honra el campo morir (39).

Finalmente, lanza su amenaza: "De mi patria en la defensa / guárdate, Rodil, de mí” (42).

A su vez, en el "Acto Segundo. Los dos rivales", también ambientado en Lima en 1825, Gilberto usa referentes andinos y clásicos para referirse a la analogía entre independentismo y aspectos personales con Rodil: "La cumbre de los Andes no colora / al padre de la luz y la alegría... Tal Israel el yugo del tirano / atado se miró: tú lo salvaste; / y con tu fuerte y justiciera mano / de Faraón las huestes destrozaste" (46).

Mientras, César demuestra un amor romántico por Margarita: "Tú mi reina serás, y yo el esclavo / que pida una caricia a tu altivez; y de la vida al encontrar el cabo / de amor tan sólo moriré a tus pies" (5l). Margarita responde: “Tu amor, César, es el viento / que aspira mi corazón, / la más plácida ilusión / de mi débil pensamiento" (52).

En este acto aparece un personaje disonante con las honras y deseos de recuperar la honra de los otros, de lógica más utilitaria y convenida. Es Vicente, quien trabaja para Rodil por dinero y conveniencia, y muestra una política de clientelaje que bien puede aplicar como crítica tanto a la época en que se ambienta la pieza como al tiempo de cuando se estrenó:

Que en política, un menguado / será aquel que de elemento / no cambie a cada momento: se venda al mejor parado // Por eso es que yo en conciencia, / al que me compra me vendo, / que el patriotismo... comprendo / cuando trae conveniencia (58). 
Las operaciones ideológicas se van haciendo más complejas cuando Rodil cuestiona la independencia en un largo discurso en prosa (quizá esa disonancia con el texto mayoritariamente en verso sea para marcar un énfasis), que también funciona como crítica a su tiempo: "Nación, ¿qué harían con lograr esa independencia que el 28 de julio proclamaron? Servir de juguete a hombres que no comprenden lo que es libertad, lo que es democracia, sino del modo que favorece su ambición" (62).

Asimismo, cuando César reta a Rodil por Margarita, reafirma la crítica a la nobleza: "El Perú es independiente, no reconocemos la nobleza de la sangre sino la del corazón y la inteligencia" (66). Rodil lo manda a detener.

En el último acto, "El sitio del Callao", ambientado en esa localidad poco después del acto anterior, Rodil ha raptado a Margarita, y se debate entre respetarla o castigarla: "Pobre niña! Tan pura y seductora / cometer una infamia horror me da... Si ella orgullosa un día te ha humillado, / Rodil, véngate en su honra de muger" (71). Rodil extorsiona a Margarita pidiéndole que se deje amar o si no fusilará a César, con ideal romántico sobre belleza. Margarita acepta sumisa: "Maldecid, Margarita, al cielo que os creó tan bella, para que la hermosura os hiciese desdichada" (74).

Poco después se produce una revelación inesperada, Gilberto le dice a César que es hijo de Rodil y María cuando este está a punto de matarlo. Se presenta esta información sin sustento ni anticipo alguno, pero el giro prefigura lo que continuará luego en obras como Libertas, o la independencia del Perú (1921) de Arturo Molinari, o Ayacucho de Giullermo Nieto (196?): un padre realista, enfrentado a un hijo patriota.

Cuando Rodil acepta que César se quede con Margarita es una analogía que justifica la independencia y el vínculo con España: 
los realistas ceden el poder, el territorio, a los patriotas, pero están ligados por sangre y cultura. Esto se reafirma cuando César defiende a Rodil de una multitud furiosa, para no ensuciar el triunfo patriota, y se le permite ir a España.

De esta manera se presenta una dicotomía entre el español con características negativas, como su crueldad, su autoritarismo o su lascivia, y la clase criolla bondadosa, permisiva y casta, tal cual se aprecia en Margarita y su familia. Sánchez Franco (2016) considera que esta obra tiene un aspecto político práctico: enfrentarse a los españoles que quisieran recuperar el poder.

Volviendo a la obra, Rodil dice que está arrepentido por haber tratado así a María y que ha buscado a su hijo. Luego de asumir sus errores y a su hijo, Rodil desea suerte a la nueva república. Cuando César retira su espada contra él y desea entregársela, le dice: "No, don César, guardadla y ojalá la esgrimáis siempre con lealtad y en defensa de vuestra patria" (79).

La obra finaliza con un militarismo muy sutil, en el coro de patriotas formado por todos los personajes menos Gilberto que ayuda a escapar a Rodil (también sin justificación). Alzan una bandera. También un ideal republicano más concreto y la misma crítica a la nobleza:

Y el furor de estraña gente / no temeremos, / que al fin / en Ayacucho y Junín / se hizo el Perú independiente... No habrá nobles en la grey, / seremos republicanos; / serán todos los peruanos / iguales ante la ley (81).

Concordamos con Sánchez Franco cuando señala que Rodil "es un drama amoroso pero también historia patriótica" (2016, p. 98). Más adelante hace una adecuada comparación entre lo femenino y la patria: 
La identificación entre mujer y patria es un tópico común en la literatura latinoamericana del siglo XIX. La mujer no solo está relacionada con la nación, sino también con el núcleo social, pues es el baluarte familiar y es una promesa de productividad siempre y cuando respete su virginidad y solo la entregue a su joven amante (100).

Otro aspecto relevante se aprecia en el monólogo final de Gilberto, que afirma valores religiosos. Acompaña en un momento música religiosa según una acotación: "Gloria, sí, gloria; pero al Ser Eterno... / Él quiso proteger a los patriotas / porque era causa santa la del pueblo" (82). Pareciera que el destino de libertad ha sido signado por Dios.

Sánchez Franco (2016) considera asimismo que la obra representa los ideales del romanticismo peruano, que busca reconciliarse con la cultura hispánica y con la religión católica. Aunque en las obras de la época de la independencia ya se apreciaba el vínculo con esta fe, es muy claro que en Palma la misma idea de patria se legitima mediante un designio divino cristiano, como se aprecia en esta proclama de Gilberto, dirigida a lo que el texto describe como una muchedumbre, pero también al público o al lector:

Así, afirma que solo la religión y, por ende, la Iglesia católica, pueden garantizar la supervivencia de la república, y en un nivel más complejo, se asocia la fe a la patria misma. Estos puntos de democracia, patriotismo, religión católica y herencia colonial que debe ser revisitada son parte del proyecto político criollo de su tiempo.

Como un detalle más, en la obra, Rodil acepta la capitulación poco antes de que se anuncie la derrota española en Ayacucho y la rendición general. En esta ucronía, se borra de la historia la incapacidad de la república de expulsar a las fuerzas españolas acantonadas en el Real Felipe durante dos años. 


\section{Conclusiones}

Las variaciones sobre la historia son peculiares al ser un hecho tan cercano a la fecha de publicación de la pieza. Y esto no es al azar ni por fines dramáticos: Rodil es un artefacto para cuestionar el presente desde el pasado, con una revisión histórica libre. Esta será la operación ideológica que emplearía Palma en sus tradiciones.

Con estética y propuesta romántica, se aproxima a un episodio particular en la lucha por la independencia ya con una distancia de veinticinco años, con la pretensión histórica propia del romanticismo, pero con una libertad para crear desde la ficción, con las sensibilidades románticas, pero también con elementos locales muy claros.

En Rodil se plantea el esquema de padre español-hijo criollo, como una metáfora de la sociedad antigua virreinal y la nueva republicana. Así, esta obra representa con lógica maniquea a los españoles como villanos incorregibles y a los criollos como héroes nobles, y una visión femenina de esta bondad.

No obstante, en esta obra se hace una primera reconciliación con España al subrayar que la nueva república es hija de una tradición cultural española. Por ejemplo, se identifica la fe católica con la república, como garante de que este nuevo sistema solo podrá subsistir gracias a la religión. Por estos motivos, en Rodil se evidencia la continuación del proyecto político criollo heredero del virreinal, que luego el mismo Palma representaría con maestría crítica en sus tradiciones. 


\section{Bibliografía}

Balta Campbell, Aída. (2000). Historia General del Teatro en el Perú. Lima: Universidad de San Martin de Porres.

Holguín Callo, Oswaldo. (1994). Tiempos de infancia y bohemia. Ricardo Palma. Lima: Fondo Editorial de la Pontificia Universidad Católica del Perú.

Palma, Ricardo. (1851). Rodil. Drama en tres actos y un prólogo. Lima: Imprenta del Correo.

(1948, [1886]). La bohemia de mi tiempo. Lima: Ediciones Hora del Hombre.

- (1953). Rodil. Drama en tres actos y un prólogo. Lima: Ediciones de Mar del Sur.

Porras Barrenechea, Raúl. (1969). El sentido tradicional de la literatura peruana. Lima: Instituto Raúl Porras Barrenechea.

Ricoeur, Paul. (1995). Teoría de la interpretación. Discurso y excedente de sentido. México: Siglo XXI.

Rivera Saavedra, Juan. (2005). Apuntes para una Historia del teatro peruano. Lima: Universidad Alas Peruanas.

Sánchez Franco, Moisés. (2016). «La representación de la mujer y de la patria en Rodil, de Ricardo Palma». Escritura y pensamiento, número 38, pp. 91-108. Recuperado de: http://revistasinvestigacion.unmsm. edu.pe/index.php/letras/article/view/13704/12147

Silva-Santisteban Ubillús, Ricardo (comp.). (2001). Antología general del teatro peruano, volumen 4: Teatro republicano. Siglo XIX. Lima: Banco Continental y Pontificia Universidad Católica del Perú. 
Sotomayor Roggero, Carmela. (1990). Panorama y tendencias del teatro peruano. Lima: Concytec.

Valero Juan, Eva. (2005). «El costumbrismo y la bohemia romántica en el Perú: un tránsito hacia la 'tradición'». Anales de Literatura Española, número 18, pp. 351-366.

Recibido el 19 de enero del 2019

Aprobado el 20 de enero del 2019 